\begin{abstract}
Iranica
Abstracta Iranica Revue bibliographique pour le domaine irano-aryen

Volume 34-35-36 | 2017

Comptes rendus des publications de 2011-2013
\end{abstract}

\title{
Rika Gyselen (éd.). Objets et documents inscrits en pārsig
}

Julien Cuny

\section{(2) OpenEdition \\ Journals}

\section{Édition électronique}

URL : http://journals.openedition.org/abstractairanica/42314

DOI : 10.4000/abstractairanica.42314

ISSN : 1961-960X

Éditeur :

CNRS (UMR 7528 Mondes iraniens et indiens), Éditions de l'IFRI

Référence électronique

Julien Cuny, "Rika Gyselen (éd.). Objets et documents inscrits en pārsīg », Abstracta Iranica [En ligne], Volume 34-35-36 | 2017, document 39, mis en ligne le 30 juillet 2017, consulté le 03 octobre 2020. URL : http://journals.openedition.org/abstractairanica/42314 ; DOI : https://doi.org/10.4000/ abstractairanica.42314

Ce document a été généré automatiquement le 3 octobre 2020.

Tous droits réservés 


\title{
Rika Gyselen (éd.). Objets et documents inscrits en pārsīg
}

\author{
Julien Cuny
}

\section{RÉFÉRENCE}

Rika Gyselen (éd.). Objets et documents inscrits en pärsīg. Bures-sur-Yvette, Groupe pour l'Étude de la Civilisation du Moyen-Orient, 2012, 218 p. (Res Orientales, XXI)

1 Ce volume des Res Orientales est entièrement consacré à la civilisation sassanide. Dans son avant-propos, l'éditrice milite pour l'utilisation du terme pārsìg pour désigner le moyen-perse sassanide au lieu de l'habituel pehlevi jugé plus ambigu. L'apport le plus significatif (deux contributions de P. Gignoux et R. Gyselen) est la publication de 15 documents juridiques issus d'une 'archive' du Tabaristan du VIII ${ }^{\mathrm{e}} \mathrm{s}$. de n.è. tous datés au jour près dans l'ère post-Yazdgird (la collection est constituée au total de 29 documents, une seconde livraison est parue dans le volume suivant des Res Orientales). Certains sont encore scellés de leur bulle, notamment par un sceau de mowūh (=mgwh, précédemment transcrit maguh), ce qui démontre que cette administration, uniquement attestée par la sigillographie, est bien impliquée dans l'appareil judiciaire. Ces actes et lettres sont les premiers textes de la pratique judiciaire connus à ce jour pour la civilisation (post-) sassanide. Dans un troisième article, R. Gyselen en profite pour livrer une utile synthèse des données disponibles à ce jour concernant l'histoire administrative de la région du Tabaristan jusqu'aux dynasties indépendantes des premiers siècles de l'Islam.

2 D'autres contributions traitent de divers objets inscrits : R. Gyselen livre dans deux articles la publication de deux collections de bulles administratives (British Museum, Ahmad Saeedi) dont certaines empreintes avaient déjà fait l'objet d'études spécifiques (cf. le c.r. $n^{\circ} 37$ dans cette même rubrique), d'autres restaient inédites et apportent des données nouvelles sur la géographie historique de l'empire sassanide (longévité de l'administration de šahrāb à Hamadān et à Gay, déjà attestée au $\mathrm{III}^{\mathrm{e}} \mathrm{s}$., contiguïté des 
provinces de Weh-Kawād et Weh-Ardašīr, et plusieurs nouveaux noms de cantons). Toujours dans le domaine de la sigillographie, on notera l'essai de lecture des " monogrammes (à lettres) ", très novateur et convaincant, proposé par R. Gyselen et $\mathrm{Y}$. Monsef. C'est assurément la tentative la plus aboutie à ce jour. F. Baratte, O. Bopearachchi, R. Gyselen et N. Sims-Williams font connaître un intéressant plat d'argent de tradition iconographique et stylistique romaine mais présentant deux inscriptions, l'une en pārsìg, l'autre en bactrien. Des hypothèses sont proposées sur son lieu et son contexte de fabrication et sur son histoire. Enfin, M.I. Mochiri étudie le monnayage attribuable à Husraw III après avoir exclu du corpus de référence, à l'issue d'une étude détaillée des techniques des faussaires modernes, de nombreuses monnaies «trafiquées ».

\section{AUTEURS}

JULIEN CUNY

Musée du Louvre 